\title{
The Clinical Characteristics of Patients with Embolic Strokes among Indonesian Subjects
}

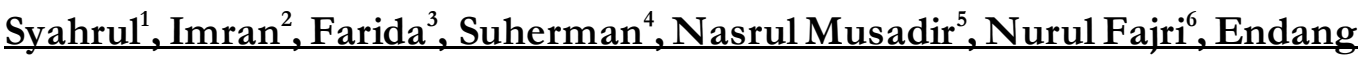 \\ Mutiawati ${ }^{7}$, Nova Dian Lestari ${ }^{8}$ \\ 1,2,3,4,5,6,7,8Department of Neurology, Faculty of Medicine, Universitas Syiah Kuala, Dr. Zainoel Abidin \\ Public Hospital, Banda Aceh, Indonesia \\ Email: syahrulsps@unsyiah.ac.id
}

\begin{abstract}
:
Stroke accounts for $10 \%$ of the world's deaths and causes severe long-term disabilities. Twenty-six million people world wide experience a stroke each year. Two-thirds represents cerebral ischemia. Age, a history of stroke or transient ischemic attack, hypertension, diabetes and heart failure characterize a stroke. Early detection with a proper treatment could improve clinical outcomes in such cases.
\end{abstract}

Keywords:

clinical characteristics; stroke; patients with embolic

\section{Introduction}

Globally, stroke is the second leading cause of death. The incidence of stroke is around 800,000 people annually. Stroke is also the leading cause of disability. The incidence of stroke has declined, but the morbidity has increased. Due to longer life expectancy, the lifetime risk of stroke is higher in women. At least 5 million people worldwide die from strokes and millions of others remain disabled. A stroke or cerebrovascular accident is an acute compromise of the cerebral perfusion or vasculature. Stroke affects men and women equally and causes major social and economic burdens to society with direct costs above $\$ 3$ billion annually in Canada. Approximately, $85 \%$ of strokes is ischemic and the rest is hemorrhagic. Ischemic etiologies can further be divided into embolic, thrombotic, and lacunar. In general, the common risk factors for stroke include hypertension, diabetes, smoking, obesity, atrial fibrillation, and drug use. Of all the above risk factors, hypertension is the most common modifiable risk factor for stroke.

The etiology of ischemic stroke is due to either a thrombotic or embolic event that causes a decrease in blood flow to the brain. According to Ekerikevwe (2020), stroke known in medical terms as Cerebrovascular Accident (CVA), is one of the leading causes of morbidity and mortalityaround the world and it imposes enormous economic burden on individuals and society. In a thrombotic event, the blood flowing to the brain is obstructed within the blood vessel due to the dysfunction within the vessel itself, usually secondary to atherosclerotic disease, arterial dissection, fibromuscular dysplasia, or infla mmatory condition. In an embolic event, debris from certain area in the body blocks blood flow through the affected vessel. 2 The etiology of stroke affects both prognosis and outcomes. In thrombosis, there is an obstructive process preventing the blood flow to some regions of the brain. Risk factors include atherosclerotic disease, vasculitis, or arterial dissection. Embolic events occur when there is a clot originating from another location in the body. Most commonly, the source of the clot is the valve or chambers of the heart. For example, it is when a clot is formed within the atria in atrial fibrillation and dislodges into the arterial vascular supply. Other less frequent causes include venous, septic, air, or fat emboli. Lacunar infarcts are usually discovered in the subcortical areas of the brain, occuring due to a small vessel disease. The proposed mechanism is a perforating artery in the subcortical region causing the blood vessel occlusion. 


\section{Research Method}

This is a retrospective cross-sectional study design. The study collected data from Februari to April 2019 among patients diagnosed and treated for embolic strokes admitted in the hospital. The follow-up for clinical information, treatment, and prognosis was also analyzed.

\section{Result and Discussion}

\subsection{Result}

The researcher gathered 35 cases of embolic strokes consisting of 15 males (43\%) and 20 females $(57 \%)$ with an average age of $>66$ years. Patients' characteristics were as follows. The main complaints were limb weakness and parese cranial nerve with $60 \%$ (21 patients) suffering a headache, and 43\% (15 patients) vomiting. The major risk factors were hypertension $(63 \%)$ and other with diabetes mellitus, smoking history recurrent stroke. GCS scores found during the examination were 29 patients presented with $\geq 9$ and 6 patients with $\leq 8$ score. Laboratory findings indicated an increase of leukocyte count (54\%) and high segmented neutrophils count (57\%). The radiology findings were 22 patients with MCA, 6 patients with MCA, PCA and 4 patients with ACA, MCA, and PCA. The therapy for patients was $72 \%$ with lovenox and $28 \%$ with clopidogrel as illustrated in the Figure (Table Baseline Characteristics).

Table 1. Baseline Characteristics

\begin{tabular}{|l|c|c|}
\hline \multicolumn{1}{|c|}{ Variables } & Total $(\mathrm{n})$ & Percentage $(\%)$ \\
\hline Male & 15 & 43 \\
\hline Female & 20 & 57 \\
\hline $30-45$ & 5 & 14 \\
\hline $46-55$ & 8 & 23 \\
\hline $56-65$ & 7 & 20 \\
\hline$>66$ year old & 15 & 43 \\
\hline Unconsciousness & 6 & 17 \\
\hline Headache & 21 & 60 \\
\hline Vomiting & 15 & 43 \\
\hline Limb weakness & 35 & 100 \\
\hline Parese of cranial nerve & 35 & 100 \\
\hline Hypertension & 22 & 63 \\
\hline Diabetes Mellitus & 4 & 12 \\
\hline Smoking history & 15 & 43 \\
\hline Recurrent of stroke & 8 & 23 \\
\hline Pneumonia & 5 & 15 \\
\hline Kidney disease & 3 & 8 \\
\hline Atrial fibrillation & 21 & 60 \\
\hline STEMI & 5 & 15 \\
\hline Cardiomegaly & 17 & 48 \\
\hline Pneumonia & 5 & 15 \\
\hline Normal & 13 & 37 \\
\hline
\end{tabular}




\begin{tabular}{|c|c|c|}
\hline \multicolumn{3}{|l|}{ Brain CT scanning } \\
\hline ACA, MCA, PCA & 4 & 11 \\
\hline ACA,MCA & 1 & 3 \\
\hline MCA,PCA & 6 & 17 \\
\hline MCA & 22 & 63 \\
\hline PCA & 1 & 3 \\
\hline Hemorrhagic transformation & 1 & 3 \\
\hline \multicolumn{3}{|l|}{ NIHSS } \\
\hline $1-4$ & 0 & 0 \\
\hline $5-15$ & 8 & 23 \\
\hline $16-20$ & 21 & 60 \\
\hline$>21$ & 6 & 17 \\
\hline \multicolumn{3}{|l|}{ Glasgow Coma Scale (GCS) } \\
\hline $13-15$ & 25 & 72 \\
\hline $9-12$ & 4 & 12 \\
\hline $4-8$ & 5 & 14 \\
\hline 3 & 1 & 3 \\
\hline \multicolumn{3}{|l|}{ Glasgow Outcome Scale (GOS) } \\
\hline $13-15$ & 25 & 72 \\
\hline $9-12$ & 4 & 12 \\
\hline Enoxaparin sodium injection & 25 & 72 \\
\hline Clopidogrel $75 \mathrm{mg}$ & 10 & 28 \\
\hline Discharged & 29 & 83 \\
\hline Died & 6 & 1 \\
\hline
\end{tabular}

Table 2. Laboratory Findings

\begin{tabular}{|c|c|c|}
\hline Variables & Total (n) & Percentage $(\%)$ \\
\hline Anemia & 9 & 26 \\
\hline Normal & 26 & 74 \\
\hline \multicolumn{3}{|l|}{ Serum Platelet } \\
\hline$<150.000$ & 5 & 14 \\
\hline $150.000-450.000$ & 29 & 83 \\
\hline$>450.000$ & 1 & 3 \\
\hline \multicolumn{3}{|l|}{ Serum Haematocrit } \\
\hline$<37$ & 9 & 26 \\
\hline $37-47$ & 23 & 66 \\
\hline$>47$ & 3 & 8 \\
\hline \multicolumn{3}{|l|}{ Serum Erythrocyte } \\
\hline$<4,2$ & 8 & 23 \\
\hline $4,2-5,4$ & 21 & 60 \\
\hline$>5,4$ & 6 & 17 \\
\hline \multicolumn{3}{|l|}{ Serum Leukocyte } \\
\hline $4,5-10,5$ & 16 & 46 \\
\hline$>10,5$ & 19 & 54 \\
\hline Plasma Glucose (mg & & \\
\hline
\end{tabular}




\begin{tabular}{|c|c|c|}
\hline$<200$ & 30 & 86 \\
\hline$>200$ & 5 & 14 \\
\hline \multicolumn{3}{|c|}{$\mathrm{BUN}(\mathrm{mg} / \mathrm{dl})$} \\
\hline $13-43$ & 32 & 92 \\
\hline$>43$ & 3 & 8 \\
\hline \multicolumn{3}{|c|}{ Serum Creatinine $(\mathrm{mg} / \mathrm{dl})$} \\
\hline $0,51-0,95$ & 32 & 92 \\
\hline$>0,95$ & 3 & 8 \\
\hline \multicolumn{3}{|c|}{ Serum Sodium $(\mathrm{mEq} / \mathrm{l})$} \\
\hline$<132$ & 2 & 6 \\
\hline $132-146$ & 27 & 77 \\
\hline$>146$ & 6 & 17 \\
\hline \multicolumn{3}{|c|}{ Serum Potassium $(\mathrm{mEq} / \mathrm{l})$} \\
\hline$<3,7$ & 3 & 8 \\
\hline $3,7-5,4$ & 32 & 92 \\
\hline \multicolumn{3}{|c|}{ Serum Chloride (mEq/l) } \\
\hline$<98$ & 3 & 8 \\
\hline $98-106$ & 25 & 72 \\
\hline$>106$ & 7 & 20 \\
\hline \multicolumn{3}{|c|}{ Serum Monocyte } \\
\hline $2-8$ & 32 & 92 \\
\hline$>8$ & 3 & 8 \\
\hline \multicolumn{3}{|c|}{ Serum Lymphocyte } \\
\hline $20-40$ & 34 & 97 \\
\hline$>40$ & 1 & 3 \\
\hline \multicolumn{3}{|c|}{ Serum Neutrophils Segmented } \\
\hline $50-70$ & 15 & 43 \\
\hline$>70$ & 20 & 57 \\
\hline \multicolumn{3}{|c|}{ Serum Eosinophils } \\
\hline $0-6$ & 33 & 94 \\
\hline$>6$ & 2 & 6 \\
\hline \multicolumn{3}{|c|}{ Serum Basophils } \\
\hline $0-2$ & 35 & 100 \\
\hline
\end{tabular}

\subsection{Discussion}

The study collected 35 cases of embolic strokes from patients admitted in the hospital from Februari to April 2019, consisting of 15 male (43\%) and 20 females (57\%) with an average age of $>66$ years. Stroke is the second most common cause of mortality and third most common cause of disability worldwide. Globally, $68 \%$ of all strokes are ischemic and $32 \%$ are hemorrhagic.11,12 Data regarding prevalence of stroke in India is lacking. However, it can be extrapolated from the data available from the West. In a study by Banerjee et al,. in 2001, the crude prevalence rate of stroke in India was 147/100,000 and the annual incidence rate was 36/100,000. Due to longer life expectancy, the lifetime risk of stroke is higher in women. Women have a substantially higher age-adjusted prevalence rate $(564 / 100,000$ for 
women vs 196/100,000 for men) and incidence rate (204/100,000 for women vs 36/100,000 for men). Overall prevalence of stroke ranges from 147-922/100,000 in various studies.

Research states that men are more susceptible to ischemic strokes, while women are more likely to develop hemorrhagic strokes with twice the risk of death than men are. Important risk factors modified in ischemic stroke are hypertension, high cholesterol, diabetes, smoking, obesity, and lack of physical activity. Data regarding risk on gender have revealed that men have a higher prevalence of risk factors, such as smoking, high cholesterol, coronary arterial disease, and peripheral arterial disease.16 Studies demonstrate that women experience neuroprotective effects before menopause related to the estrogen hormones, they also tend to have a lower risk of stroke when 40 to 75 years compared to men, but after 75 years, women experience about $50 \%$ greater risk for stroke than men.

According to Sari (2020) stroke is a disorder of blood vessels or rupture of blood vessels in the brain so that blood supply in the brain becomes disrupted and results in brain cells die because they do not get oxygen and nutrients. Patient's characteristics were as follows. The main complaints were limb weakness and parese cranial nerve, $60 \%$ (21 patients) with a headache, and 43\% (15 patients) vomiting. The major risk factors were hypertension $63 \%$ and other with diabetes mellitus, smoking history recurrent stroke. GCS scores found during the examination were 29 patients presented with $\geq 9$ and 6 patients with $\leq 8$ score.

Clinical symptoms of stroke are the appearance of neurological deficits with sudden onset. Symptoms depend on the anatomic area of the arteries in the affected brain. $90 \%$ of strokes occur in the supratentorial area with the following appearance of symptoms. If the lesions on the left hemisphere are aphasia, it is the right hemiparesis, the right hemianopia. In addition, if the lesions are on the right hemisphere, clinical symptoms will appear in the form of left hemiparesis, left hemispacial neglect and left hemianopia. If the lesion occurs in posterior circulation or infratentorial stroke, there will be many additional symptoms, including diplopia, bulbar muscle paralysis, dysphagia, unilateral dysmetria and incoordination, and decreased consciousness. Although headaches, facial or neck pain can be additional symptoms, strokes commonly cause no pain. The most important feature of a stroke is a sudden onset of symptoms.

A total of 25 patients with a smoking history $(38.5 \%)$ had a high risk of stroke based on the Stroke Risk Scorecard, while among non-smoking patients, there were 26 high risk patients $(40 \%)$. Smoking can also trigger atrial fibrillation, a heart condition known as a risk factor for stroke. Chemicals in cigarettes also more likely allow platelets to stick together and form blood clots. The above factors increase the risk of atherosclerosis, a condition of narrowing and hardening arteries. Afterwards, atherosclerosis can reduce blood flow and allow blood clots more easily to form. If a blood clot is in the arteries leading to the brain, the blood supply can be blocked resulting in an ischemic stroke.

Laboratory findings showed increase of leukocyte count (54\%) and high segmented neutrophils count (57\%). Radiology findings were 22 patients with MCA, 6 patients with MCA, PCA and 4 patients ACA, MCA, and PCA. Therapy for patients were $72 \%$ with enoxaparin sodium injection and $28 \%$ with Clopidogrel.

As there is an important inflammatory response during stroke events, the cells implicated in the immune system are likely to be associated with the stroke outcome. In addition, it is reported that neutrophils are related with the blood brain barrier breakdown and 
their infiltration seems to be associated with a higher inflammation and with a role in cerebral ischemia 19, and higher neutrophil counts before thrombolysis have been associated with worse 3-month outcomes. 20 However, there are few studies analyzing the relation of leukocytes (including neutrophils and lymphocytes) with acute stroke outcome. 21-23 In leukocyte count affects early stroke outcome. A total of 811 ischemic stroke patients were included in the study. NIHSS score was measured at baseline and after 72 hours, as well as at discharge, and leukocytes counts were measured within 12 hours post-stroke onset. Higher leukocytes counts were independently associated with high NIHSS scores at baseline and 72 hours, and with poor functional outcome at discharge. Therefore, leukocyte counts have an impact on subacute outcome independently of age or NIHSS at baseline.

Blood platelet counts (BPC) were previously associated with ischemic stroke risk 24, although their influence on outcome is poorly described. The study by Furlan et al.,25 described the association of abnormal BPC (such as thrombocytopenia or thrombocytosis) is associated with a long term, but not with the acute outcome. However, further studies are required to confirm these findings.

Red blood cell counts and hemoglobin levels could influence the reoxygenation during acute ischemic stroke and, in turn, the degree of neurological damage occurred. Furlan et al.,26 analyzed the influence of blood hemoglobin concentration (HGB) on stroke severity and outcome after ischemic stroke in a large cohort of 9,230 ischemic stroke patients. They found that high HGB, not the low one, was an independent predictor of an increased 7 -day mortality compared to the normal HGB. In summary, high oxygen availability in acute phase of stroke can be associated with the worse acute and subacute outcome, although more research is required.

The success of the management of acute ischemic stroke is currently based on two strategies of recanalization of blood vessels: anti-platelet agents and thrombolysis. Because most strokes are caused by thromboembolic occlusion from intracranial arteries, restoration or increased perfusion to the ischemic area is the main therapeutic strategy. The concept of "ischemic penumbra," a potentially recoverable brain tissue, allows early intervention to improve neurological symptoms, and reduce functional disability after an attack. There are many strategies suggested for the acute stroke treatment, but oral aspirin and intravenous rTPA are the only two drugs currently recommended for the treatment of acute stroke.

Aspirin administration with an initial dose of $325 \mathrm{mg}$ in 24 to 48 hours after the onset of a stroke is recommended for any acute ischemic stroke (AHA/ ASA, Class I, Level of evidence A). Procedure on applying therapy administration for thrombolysis with rTPA on acute ischemic stroke is recommended for stroke medication on the difference between the benefits and disadvantages in the management provided. Fibrinolytics with rTPA generally provide reperfusion benefit from thrombus lysis and significant repair of cerebral cells. Fibrinolytic administration is a strong recommendation as soon as possible after the diagnosis of an acute ischemic stroke is established (onset of 3 hours on intravenous administration within 6 hours of intraarterial administration).

In Boehme et al., the authors analyzed the influence of infections on acute outcome of ischemic stroke patients for the first time, with END being the primary outcome (NIHSS score increase of $\geq 2$ within 24 hours). They used a cohort of 334 patients, with 77 infected, and classified the infections as present on admission (POA, infection diagnosed within the first 24 hours) and hospital-acquired infections (HAIs, infection diagnosed after 24 hours). 


\section{Conclusion}

The study reported 35 cases of embolic strokes. Patients when arriving in the hospital were reported with the clinical profile, clinical manifestation, GCS score, brain imaging, risk factor, labotratory and outcome. However, further research is required in this field. Analysis of acute and subacute outcome is important to understand the molecular mechanisms behind the acute and long-term recovery. Eventually, the treatment to prevent the worsening after stroke is realized.

\section{References}

Banerjee TK,, Mukherjee CS,, Sarkhel A. (2001). Stroke in the Urban Population of Calcutta-and Epidemiological Study. Neuroepidemiology.

Benjamin EJ,, Blaha MJ,, Chiuve SE,, Cushman M, Das SR,, Deo R,, et al. (2017). Heart Disease and Stroke Statistics-2017 Update: A Report from the American Heart Association. Circulation.

Boehme AK, Kumar AD, Dorsey AM, Siegler JE, Aswani MS, Lyerly MJ, et al. (2013). Infections present on admission compared with hospital-acquired infections in acute ischemic stroke patients. J Stroke Cerebrovasc Dis. 2013;22:e582-e589

Chugh, Chandril. "Acute Ischemic Stroke: Management Approach.” Indian J of Crit Care Med 23, Suppl 2 (2019): S140-S146. doi:10.5005/jp-journals-10071-23192.

Ekerikevwe, K.I. (2020). Survival Analysis of the ClinicalEpisodes of Stroke Using Data from Western Delta Region of Nigeria. Britain International of Exact Sciences (BIoEx) JournalISSN: 2686-1208 (Online), 2686-1216 (Print)Vol. 2 (1):1-10.

Furlan JC, Fang J, Silver FL. (2016). Acute ischemic stroke and abnormal blood hemoglobin concentration. Acta Neurol Scand. 2016;134:123-130.

Furlan JC, Fang J, Silver FL. (2016). Outcomes after Acute Ischemic Stroke in Patients with Thrombocytopenia or Thrombocytosis. J Neurol Sci. 2016;362:198-203

Gibson CL. Cerebral Ischemic Stroke: Is Gender Important? J CBF \& Met. 2013.33(9): 13551361.

Gurol, M.E., and Kim, J.S. (2018). Advances in Stroke Prevention in 2018. J Stroke. 2018;20(2):143-144. doi:10.5853/jos.2018.01438

Hart, R.G., Diener, H.C., Coutts, S.B., Easton, J.D., Granger, C.B., O’Donnell, M.J., Sacco R.L., Connolly, S.J. (2014). Cryptogenic Stroke/ESUS International Working Group. Embolic Strokes of Undetermined Source: The Case for a New Clinical Construct. Lancet Neurol. 2014; 13:429-438. doi: 10.1016/S1474-4422(13)70310-7

Kasner SE, Lavados P, Sharma M, et al. (2018). Characterization of Patients with Embolic Strokes of Undetermined Source in the NAVIGATE ESUS Randomized Trial. J Stroke Cerebrovasc Dis 2018;27:1673-1682

Krishnamurthi RV, Moran AE, Feigin VL, Barker-Collo S, Norrving B, Mensah GA, Taylor S, Naghavi M, Forouzanfar MH, Nguyen G, Johnson CO, Vos T, Murray CJ, Roth GA., GBD (2013). Stroke Panel Experts Group. Stroke Prevalence, Mortality and DisabilityAdjusted Life Years in Adults Aged 20-64 Years in 1990-2013: Data from the Global Burden of Disease 2013 Study. Neuroepidemiology. 2015;45(3):190-202

Kumar AD, Boehme AK, Siegler JE, Gillette M, Albright KC, Martin-Schild S. (2013). Leukocytosis in patients with neurologic deterioration after acute ischemic stroke is associated with poor outcomes. J Stroke Cerebrovasc Dis. 2013;22:e111-e117.

Lozano R,, Naghavi M,, Foreman K,, Lim S,, Shibuya K,, Aboyans V,, et al. (2012). Global and regional mortality from 235 causes of death for 20 age groups in 1990 and 2010: a systematic analysis for the Global Burden of Disease Study 2010. Lancet. 
Maestrini I, Strbian D, Gautier S, Haapaniemi E, Moulin S, Sairanen T, et al. (2015). Higher neutrophil counts before thrombolysis for cerebral ischemia predict worse outcomes. Neurology. 2015;85:1408-1416.

Mello, S., Judge, S., Bradley, D., Kelly, R., and Harbison, J. (2017). "A Systematic Review of the Causes and Management of Non-thrombotic Stroke caused by Tissue Emboli," Age and Ageing 2017, vol. 46, 3.

Musuka, T.D., et al. "Diagnosis and Management of Acute Ischemic Stroke: Speed is Critical." CMAJ, 187,12 (2015): 887-93. doi:10.1503/cmaj.140355.

Nardi K, Milia P, Eusebi P, Paciaroni M, Caso V, Agnelli G. (2012). Admission Leukocytosis in Acute Cerebral Ischemia: Influence on Early Outcome. J Stroke Cerebrovasc Dis. 2012;21:819-824.

Pandian JD,, Sudhan P. (2013). Stroke Epidemiology and Stroke Care Services in India. J Stroke.

Pósfai É, Marton I, Szőke A, Borbényi Z, Vécsei L, Csomor A, et al. (2014). Stroke in Essential Thrombocythemia. J Neurol Sci. 2014;336:260-262

Samai, A.A., dan Martin-Schild S. (2015). Sex Differences in Predictors of Ischemic Stroke: Current Perspectives. Vascular Health and Risk Management. 11: 427.

Sari, A.P., Lubis, R., and Zulfendri. (2020). Determinant of Hypertension, Obesity and Smoking on Stroke Events in Hospital Patients at Regional General Hospitalof Rokan Hulu Riau District, 2018(Epidemiology and Public Health). Britain International of Exact Sciences (BIoEx) Journal Vol. 2 (1):384-389.

Strecker, J.K., Schmidt A, Schäbitz WR, Minnerup J. (2017). Neutrophil granulocytes in cerebral ischemia: evolution from killers to key players. Neurochem Int. 2017;107:117126

Tapuwa D. Musuka MBChB, Stephen B. Wilton MD, Mouhieddin Traboulsi MD MDHM. (2015). Diagnosis and management of acute ischemic stroke: speed is critical. CMAJ. 187(12):887-93.

Tian, C., Ji, Z., Xiang, W., Huang, X., Wang, S., Wu, Y., et al. (2018). Association of lower leukocyte count before thrombolysis with early neurological improvement in acute ischemic stroke patients. J Clin Neurosci. 2018;56:44-49

Topcuoglu, M.A., Liu, L., Kim, D.E., and Gurol, M.E. (2018). Updates on Prevention of Cardioembolic Strokes. J Stroke. 2018;20(2):180-196. doi:10.5853/jos.2018.00780

Tsivgoulis G, Katsanos AH, Köhrmann M, et al. (2019).Embolic strokes of undetermined source: theoretical construct or useful clinical tool? Ther Adv Neurol Disord.

Writing Group Members. Mozaffarian D, Benjamin EJ, Go AS, Arnett DK, Blaha MJ, Cushman M, Das SR, de Ferranti S, Després JP, Fullerton HJ, Howard VJ, Huffman MD, Isasi CR, Jiménez MC, Judd SE, Kissela BM, Lichtman JH, Lisabeth LD, Liu S, Mackey RH, Magid DJ, McGuire DK, Mohler ER, Moy CS, Muntner P, Mussolino ME, Nasir K, Neumar RW, Nichol G, Palaniappan L, Pandey DK, Reeves MJ, Rodriguez CJ, Rosamond W, Sorlie PD, Stein J, Towfighi A, Turan TN, Virani SS, Woo D, Yeh RW, Turner MB., American Heart Association Statistics Committee. Stroke Statistics Subcommittee. Heart Disease and Stroke Statistics-2016 Update: A Report From the American Heart Association. Circulation. 2016 Jan 26;133(4):e38-360. 